\title{
Fungal-associated molecules induce key genes involved in the biosynthesis of the antifungal secondary metabolites nunamycin and nunapeptin in the biocontrol strain Pseudomonas fluorescens In5
}

Christiansen, Line; Alanin, Katrine Skov; Phippen, Christopher B. W.; Olsson, Stefan; Stougaard, Peter; Hennessy, Rosanna C.

Published in:

Applied and Environmental Microbiology

Link to article, DOI:

10.1128/AEM.01284-20

Publication date:

2020

Document Version

Peer reviewed version

Link back to DTU Orbit

Citation $(A P A)$ :

Christiansen, L., Alanin, K. S., Phippen, C. B. W., Olsson, S., Stougaard, P., \& Hennessy, R. C. (2020). Fungalassociated molecules induce key genes involved in the biosynthesis of the antifungal secondary metabolites nunamycin and nunapeptin in the biocontrol strain Pseudomonas fluorescens In5. Applied and Environmental Microbiology, 86(21), [e01284-20]. https://doi.org/10.1128/AEM.01284-20

\section{General rights}

Copyright and moral rights for the publications made accessible in the public portal are retained by the authors and/or other copyright owners and it is a condition of accessing publications that users recognise and abide by the legal requirements associated with these rights.

- Users may download and print one copy of any publication from the public portal for the purpose of private study or research.

- You may not further distribute the material or use it for any profit-making activity or commercial gain

- You may freely distribute the URL identifying the publication in the public portal 
1 Fungal-associated molecules induce key genes involved in the biosynthesis of the antifungal 2 secondary metabolites nunamycin and nunapeptin in the biocontrol strain Pseudomonas 3 fluorescens $\operatorname{In} 5$

4

$5 \quad$ Running Title: Regulation of cyclic lipopetides in P. fluorescens In5

6 Line Christiansen ${ }^{\mathrm{a}}$, Katrine Skov Alanin $^{\mathrm{a}}$, Christopher B.W. Phippen ${ }^{\mathrm{b}}$, Stefan Olsson ${ }^{\mathrm{c}, \mathrm{d}}$, Peter $7 \quad$ Stougaard ${ }^{\mathrm{e}} \#$, Rosanna C. Hennessy ${ }^{\mathrm{a}}$

$8 \quad{ }^{\mathrm{a}}$ Department of Plant and Environmental Sciences, University of Copenhagen, Denmark

$9 \quad{ }^{b}$ Department of Biotechnology and Biomedicine, Technical University of Denmark, Denmark

10 'State Key Laboratory of Ecological Pest Control for Fujian and Taiwan Crops, College of Plant

11 Protection, Fujian Agriculture and Forestry University, Fuzhou City, Fujian Province, China

12 dPlant Immunity Center, Haixia Institute of Science and Technology, College of Life Science, Fujian

13 Agriculture and Forestry University, Fuzhou City, Fujian Province, China

$14{ }^{\mathrm{e}}$ Department of Environmental Science, Aarhus University, Denmark

\#Address correspondence to Peter Stougaard, pst@envs.au.dk . 


\section{Abstract:}

Pseudomonas fluorescens In5 synthesizes the antifungal cyclic lipopeptides (CLPs) nunamycin and nunapeptin, which are similar in structure and genetic organization to the pseudomonas-derived phytotoxins syringomycin and syringopeptin. Regulation of syringomycin and syringopeptin is dependent on the two-component global regulatory system GacS/GacA, and the SalA, SyrF, and SyrG transcription factors, which activate syringomycin synthesis in response to plant signalling molecules. Previously, we demonstrated that a specific transcription factor, NunF, positively regulates the synthesis of nunamycin and nunapeptin in $P$. fluorescens $\operatorname{In} 5$ and that the $n u n F$ gene is upregulated by fungal-associated molecules. This study focusses on further unravelling the complex regulation governing CLP synthesis in $P$. fluorescens In5. Promoter fusions were used to show that the specific activator NunF is dependent on the global regulator of secondary metabolism GacA and is regulated by fungal-associated molecules and low temperatures. In contrast, GacA is stimulated by plant signalling molecules leading to the hypothesis that $P$. fluorescens is a hyphosphereassociated bacterium encoding transcription factor genes that respond to signals indicating the presence of fungi and oomycetes. Based on these findings, we present a model for how synthesis of nunamycin and nunapeptin is regulated by fungal- and oomycete-associated molecules.

\section{Importance:}

Cyclic lipopeptide (CLP) synthesis gene clusters in pseudomonads display a high degree of synteny and the structure of the peptides synthesized is very similar. Accordingly, the genomic island encoding the synthesis of syringomycin and syringopeptin in $P$. syringae pv. syringae closely resembles that of $P$. fluorescens In5, which code for synthesis of the antifungal and anti-oomycete peptides nunamycin and nunapeptin, respectively. However, the regulation of syringomycin and syringopeptin synthesis is different from that of nunamycin and nunapeptin synthesis. While CLP synthesis in the plant pathogenic $P$. syringae pv. syringae is induced by plant signalling molecules, such compounds do not significantly influence synthesis of nunamycin and nunapeptin in $P$. 
43 fluorescens In5. Instead, fungal-associated molecules positively regulate anti-fungal peptide 44 synthesis in P. fluorescens In5 while the synthesis of the global regulator GacA in P. fluorescens 45 In5 is positively regulated by plant signal molecules but not fungal-associated molecules.

46 
Members of the genus Pseudomonas are ubiquitous inhabiting many environments including agricultural soils where they may promote plant growth and health, and suppress plant pathogens (1-4). One of the major mechanisms by which pseudomonads suppress plant pathogens such as fungi and oomycetes is through the production of a variety of secondary metabolites capable of inhibiting fungal growth. A very large number of publications describe bioactive compounds produced by pseudomonads most notably cyclic lipopeptides (CLPs), 2,4-diacetylphloroglucinol (DAPG), phenazines (PHZs), pyrrolnitrin (PRN), pyoluteorin (PLT), 2,5-dialkylresorcinol, quinolones, gluconic acids, rhamnolipids, siderophores, and hydrogen cyanide (4-6). Some groups produce several of the bioactive compounds whereas others only synthesize a selection of the compounds. Zhao and coworkers performed an in silico analysis of genome sequences representing a variety of pseudomonads (7). They found that strains of Pseudomonas protegens produced CLPs, siderophores, DAPG, PRN, PLT and other bioactive compounds, some strains of $P$. brassicacearum, $P$. fluorescens, and $P$. thivervalensis synthesized siderophores, and DAPG but not CLPs, PRN, or PLT, whereas strains affiliated to $P$. syringae, $P$. brassicacearum, $P$. fluorescens, $P$. corrugata, and P. poae only produced CLPs and siderophores but not DAPG, PRN, or PLT. The CLPs produced by this last group comprise syringomycin/syringopeptin (from $P$. syringae pv. syringae) (8), brasmycin/braspeptin (from Pseudomonas sp. 11K1) (7), nunamycin/nunapeptin (from P. fluorescens In5) (9), cormycin/corpeptin (from $P$. corrugata) (10), and thanamycin/thanapeptin (from Pseudomonas sp. SH-C52) (11) (Fig. S1). The peptide encoding genes from these pseudomonads show a high degree of synteny (Fig. S1) and thus, the peptides synthesized are very similar: all the -mycin peptides are cyclic and composed of nine amino acids and the -peptins are 22 amino acid cyclic peptides (7). In addition to genes involved in the synthesis of thanamycin and thanapeptin in Pseudomonas sp. SH-C52, the large genomic island also contained genetic information for synthesis of antimicrobial dipeptides, brabantamide A, B, and C (11-12). Mining the genome sequences of pseudomonads similar to Pseudomonas sp. SH-C52 
revealed similar brabantamides-like synthesis genes (Fig. S1) and in this paper, we also show that

97 P. fluorescens In5 is capable of synthesizing brabantamide-like compounds.

Synthesis of secondary metabolites in pseudomonads is complex and regulated by a plethora of molecules and systems. The two component global regulatory system GacS/GacA has been shown to activate a number of cellular processes in Pseudomonas species (13-15) including synthesis of lipopeptides and other virulence factors (16-19). The GacS/GacA system often works together with the Rsm system (repressor proteins RsmA and RsmE in addition to small RNAs rsmY and $\operatorname{rsmZ}$ ) $(20,21)$ and $N$-acylhomoserine lactone ( $N$-AHL)-mediated quorum sensing systems $(22,23)$. In addition to the overarching GacS/GacA system, other genes may regulate secondary metabolite production, for example special sigma factors (24), D-3-phosphoglycerate dehydrogenase, an Hsp70 protein family chaperone encoded by dnaK, and PrtR, an anti-sigma factor and transmembrane activator (25). Finally, genes that encode specific transcriptional regulators are often found in the large genomic islands that comprise all genes necessary for the synthesis of secondary metabolites. In $P$. syringae pv. syringae the regulatory genes salA, syrF, and syrG involved in synthesis of syringomycin and syringopeptin are located next to the syringomycin encoding gene, syrE (26), and in $P$. fluorescens In5 the $n u n F$ gene homologous to $s y r F$ in $P$. syringae pv. syringae is situated next to the nunamycin genes nunD and nunE (Fig. S1) (27). In P. syringae pv. syringae, the GacS/GacA system positively regulates the expression of the salA gene (18) and the salA gene product positively regulates the $s y r F$ and $s y r G$ genes which in turn positively regulate syringomycin synthesis genes (29). In an early paper from 1991, Mo and Gross showed that one of the genes, $s y r B$, involved in syringomycin synthesis was induced by plant signal molecules in accordance with the fact that $P$. syringae pv. syringae is a plant pathogen (29). This observation was confirmed in a later publication in which Wang et al. showed by microarray and promotor fusion analyses that the whole syr-syp region was upregulated by the plant phenolic glucosides arbutin, salicin and phenyl$\beta$-D-glucopyranoside (30). 
We have previously shown that in $P$. fluorescens In5, NunF, a homolog to SyrF, positively regulates synthesis of both nunamycin and nunapeptin and that nunF expression was strongly upregulated in response to both carbon sources indicating the presence of a fungus (27) and during interaction with the fungus Fusarium graminearum (31). In this study, we investigate the induction pattern of In5 nunF and gacA in relation to fungal and plant signal molecules, and we show that In5 gacA is slightly upregulated by arbutin but not by fungal molecules whereas nunF is upregulated only by fungal signaling molecules but not by plant phenolics. Finally, we summarize our results in a model for how nunamycin/nunapeptin is regulated when the bacterium comes into contact with a fungus.

107

\section{Results and Discussion}

109 nunapeptin synthesis (27).

120

\section{GacA and NunF are positive regulators of nunamycin and nunapeptin}

Comparison of genomic islands encoding cyclic peptides in different Pseudomonas strains reveals a large degree of synteny between the regions that encode the synthesis of e.g. nunamycin/-peptin, brasmycin/-peptin, syringomycin/-peptin, thanamycin/-peptin, and cormycin/-peptin (Supplementary Fig. S1). Not only nonribosomal peptide synthetase genes show synteny, regulatory genes that typically are located adjacent to the synthetase genes also display synteny $(7,9,11)$. In $P$. syringae pv. syringae B301D, production of syringomycin and syringopeptin was shown to be controlled by the LuxR-type regulatory genes salA, syrF, and $\operatorname{syr} G(20)$ and in $P$. fluorescens In5, $n u n F$, a LuxR homolog to $s y r F$, was shown to be one of the key regulators of nunamycin and

Here, we show that synthesis of nunamycin, nunapeptin, and brabantamides is regulated by the Gac-system. Fig 1A shows that nunamycin, nunapeptin, and brabantamide-like compounds are produced in a $P$. fluorescens In5 wild type strain but not in a gacA knock-out mutant, resulting in 
inability of the mutant to inhibit the growth of both fungi and oomycetes (Fig. 1B). In a previous publication, we showed that synthesis of nunamycin and nunapeptin was also dependent on the presence of an intact nunF gene, and we subsequently demonstrated that $n u n F$-promotor::mCherry fusions can be used to monitor the expression of the gene encoding the activator NunF (27). We have therefore used the nunF::mCherry and gacA::mCherry fusions to examine the transcriptional activity from the $n u n F$ and $g a c A$ promotors in relation to the genetic background and supplemented carbon source. Fig. 1C shows that the $n u n F$ promotor was switched on after ca. 13-14 hours after inoculation and induction in the wild type strain but it was totally inactive in a gacA mutant. Activity of the $n u n F$ promotor was lowered to ca. $14 \%$ in a $n u n F$ knock out mutant indicating that NunF was positively autoregulating its own expression. Expression from the gacA promotor was analyzed similarly. In wild type cells, the gacA promotor was gradually activated ca. 9 hours after inoculation and induction and transcription continued for ca. 9-10 hours in contrast to transcription from the nunF promotor that only lasted ca. 3 hours. The gacA promotor showed no dependency on $n u n F$ since the level of mCherry fluorescence in a $n u n F$ knock out mutant was similar to that in wild type cells. However, the gacA promotor was upregulated ca. $100 \%$ in a gacA mutant indicating that synthesis of GacA was also autoregulated but in a negative way with GacA acting as a repressor of its own expression (Fig. 1C).

\section{Regulation of gacA and nunF promotors by plant and fungal associated molecules}

Mo and Gross (1991) showed that plant signal molecules activated the $\operatorname{syr} B$ gene, which is required for syringomycin production by $P$. syringae pv. syringae, and we demonstrated that in $P$. fluorescens In5 the nunF gene, which is an activator for synthesis of nunamycin and nunapeptin, may be regulated by fungal-associated molecules $(27,29)$. Here, we analyze the activity of the gacA and $n u n F$ promotors from strain In5 in relation to fungal (trehalose, glycerol) and plant (arbutin, salicin, phenyl- $\beta$-D-glucopyranoside) associated molecules. Fig. 2 A shows that the gacA promotor from $P$. fluorescens In5 responded to the plant signal molecules, arbutin and phenyl- $\beta$-D- 
glucopyranoside, whereas the fungal associated molecule trehalose showed no induction as the expression pattern was similar to that of water or DMSO addition. The nunF promotor on the other hand showed no induction with the plant signal molecules, arbutin, salicin, or phenyl- $\beta$-Dglucopyranoside but was induced by trehalose (Fig. 2B) and glycerol (Fig. 5). Helicin and esculin that showed no activity on the $\operatorname{syr} B$ promotor in the Mo and Gross study (29) were also tested in this study but no induction of nunF was observed (data not shown).

\section{Crude fungal extracts upregulate nunF but not gacA promotors in P. fluorescens In5.}

Since fungal but not plant-associated molecules induced the nunF promotor, we tested if crude fungal extracts could also activate the promotor. Fig. 3A shows that the gacA promotor was not induced by extracts derived from the plant pathogen Fusarium culmorum or the fungal biocontrol agents Clonostachys rosea or Trichoderma harzianum. However, the nunF promotor was significantly upregulated by extracts from all three fungi, irrespectively if they were pathogenic or non-pathogenic. Heat inactivation of the extracts lowered the level of induction to ca. $60-70 \%$ of the untreated extracts, but the level was still ca. 100\% higher than activation with trehalose (Fig. 3B). Similar results were obtained when testing extracts obtained from fungal phytopathogen Rhizoctonia solani and the plant pathogenic oomycete Pythium aphanidermatum (Fig. S2)

nunF and syrF promotors respond differently to fungal extracts and molecules.

NunF and SyrF have been shown to activate the synthesis of nunamycin/-peptin and syringomycin/peptin, respectively in $P$. fluorescens In5 and $P$. syringae pv. syringae (26-28). We cloned the $s y r F$ promotor from P. syringae pv. syringae B728a in a promotor::mCherry fusion vector similar to the vector with nunF promotor:: $m$ Cherry fusion and transformed the $s y r F$ and nunF promotor fusions into $P$. syringae and $P$. fluorescens In5, respectively in order to compare the induction of $s y r F$ compared to that of nunF. As observed previously, the nunF promotor was induced by a Fusariumderived extract and by trehalose (Figure 4A). The $s y r F$ promotor in $P$. syringae displayed a lower 
176

177

178

179

180

181

182

induction by the fungal extract and hardly any induction with the fungal associated molecule trehalose.

nunF promotor expression and production of nunamycin, nunapeptin, and brabantamides is temperature dependent.

All the above experiments were conducted at $28^{\circ} \mathrm{C}$, the optimal growth temperature for $P$. fluorescens In5. However, previous experiments have shown that inhibition of fungi and oomycetes is more efficient at $10-15^{\circ} \mathrm{C}$ compared to $20^{\circ} \mathrm{C}$ (32). As a result, we also investigated the effect of temperature on the expression of the $n u n F$ promotor again using promotor::mCherry fusions, and quantified the production of nunamycin, nunapeptin, and brabantamide-like compounds using LCMS. Four experiments were run in parallel at $10^{\circ} \mathrm{C}, 15^{\circ} \mathrm{C}, 20^{\circ} \mathrm{C}$, and $28^{\circ} \mathrm{C}$ and promotor activities were followed over ca. 47 hours and at the end, secondary metabolites were measured by LC-MS. The $n u n F$ promotor fusions showed maximal induction at $20^{\circ} \mathrm{C}$, ca. $75 \%$ at $15^{\circ} \mathrm{C}$ and ca. $20-25 \%$ activity was measured at $28^{\circ} \mathrm{C}$ (Fig. 5). At $10^{\circ} \mathrm{C}$, the cells grew very slowly and no induction was observed after 47 hours. Similarly, expression from the gacA promotor was measured at the four temperatures. No expression from the gacA promotor could be monitored at $10^{\circ} \mathrm{C}, 15^{\circ} \mathrm{C}$, or $20^{\circ} \mathrm{C}$ whereas at $28^{\circ} \mathrm{C}$, gacA expression was observed as previously described (Figs. 1, 2, 3). The fact that only the $n u n F$ promotor was induced at $10^{\circ} \mathrm{C}, 15^{\circ} \mathrm{C}$, or $20^{\circ} \mathrm{C}$, temperatures normally found in Greenlandic soils, could indicate that NunF is the real activator of production of nunamycin, nunapeptin, and brabantamides in $P$. fluorescens In5. GacA, although essential for peptide production (Fig. 1), may serve other global functions. Also shown in Fig. 5 is induction with the fungal associated molecules, trehalose and glycerol, and with glucose. The nunF promotor fusion was upregulated with all three compounds whereas the gacA promotor was not induced. Glucose showed the highest induction of $n u n F$ at $15^{\circ} \mathrm{C}$ and at $20^{\circ} \mathrm{C}$, whereas glycerol was the best inducer at $28^{\circ} \mathrm{C}$. The reason for this difference could be due to different rates of uptake of glucose, glycerol, and trehalose and/or different metabolic efficiencies. 
In a parallel experiment, cells were cultivated at $10^{\circ} \mathrm{C}, 15^{\circ} \mathrm{C}, 20^{\circ} \mathrm{C}$, and $28^{\circ} \mathrm{C}$ and supplemented with either glucose, trehalose, or glycerol. Supernatants were extracted and the presence of nunamycin, nunapeptin, and brabantamide-like compounds was measured by LC-MS. Fig. 6 shows that all three secondary metabolites were produced with glucose, glycerol, and trehalose as inducers. The optimal temperature for production was at $15^{\circ} \mathrm{C}$ followed by $10^{\circ} \mathrm{C}$ and $20^{\circ} \mathrm{C}$. No or almost no synthesis of nunamycin, nunapeptin or brabantamide-like compounds was observed at $28^{\circ} \mathrm{C}$. This result supports the previous observation that maximal inhibition of fungal and oomycete growth was at $10-15^{\circ} \mathrm{C}$ but is in contradiction with the promotor fusion results above. However, the promotor fusion experiments measure transcription, whereas LC-MS and inhibition experiments also monitor post-translational processes notably ribosomal translation of the large non-ribosomal peptide synthetase complexes, non-ribosomal peptide synthesis, and transport of the peptides.

\section{Model for synthesis of secondary metabolites in P. fluorescens In5 interacting with fungi.}

P. syringae pv. syringae is a plant pathogen and thus, synthesis of the phytotoxins syringomycin and syringopeptin is induced by plant signalling molecules. In contrast, $P$. fluorescens In5, a fungal pathogen, does not respond to plant-associated molecules but rather to molecules indicating the presence of fungi and/or oomycetes. The model below (Fig. 7) explains how synthesis of nunamycin and nunapeptin is regulated as a consequence of interaction between the bacterium and its host fungus.

Step 1: Bacterium and fungus are far away from each other. Neither glycerol or trehalose (or glucose) are common in soil since they are readily metabolized by bacteria.

In bacterium: NunF and GacA regulators and nunamycin and nunapeptin are expressed constitutively at very low levels.

In fungus: The main carbon storage is fat. Glucose, glycerol, and trehalose concentrations are relatively low. Turgor is high. 
Step 2: Bacterium and fungus approach each other and come close.

In bacterium: GacA is expressed at low, constitutive level; NunF is induced by the leaking glucose, glycerol, and trehalose from fungal hyphae. Nunamycin and nunapeptin still expressed constitutively at very low level.

In fungus: The membrane starts to leak. Fat is converted to glycerol to try to restore turgor pressure and trehalose is synthesized to protect membranes and proteins from apparent drying. Glycerol and trehalose (and glucose) leaks out of the fungus and is taken up by the bacterium.

Step 3: Bacterium and fungus have been in close contact for some time.

In bacterium: GacA is still expressed at low, constitutive level; NunF is expressed at high level due to the leaking glucose, glycerol, and trehalose and induces production at high levels and export of nunamycin and nunapeptin.

In fungus: The membrane leaks more. The fungus tries to restore turgor pressure as before but the now more leaking membrane makes turgor pressure drop. The fungus starts to die while the bacterium growth rate increases.

\section{Summary}

In this study, promoters from $g a c A$ and $n u n F$ genes that regulate CLP synthesis in $P$. fluorescens In5 were fused to a reporter gene encoding the red fluorescent protein mCherry. P. fluorescens In5 cells harboring the promotor fusions were cultivated in the presence of different carbohydrates and fungal extracts and the expression from the promotors was studied by measuring the fluorescence generated. The promotor expressing the specific activator, NunF, was shown to be dependent on the global regulator of secondary metabolism, GacA, and it was regulated by fungal-associated molecules and low temperatures. In contrast, GacA was stimulated by plant signalling molecules. In a parallel experiment with the In5 nunF promotor and the homologous syrF promotor from the closely related $P$. syringae pv. syringae, it was shown that the syrF promotor responded much less 
to fungal extracts and not at all to trehalose, one of the molecules indicating the presence of fungi. This let us to hypothesize that $P$. fluorescens In5 is a hyphosphere-associated bacterium encoding transcription factor genes that respond to signals indicating the presence of fungi and oomycetes, whereas $P$. syringae pv. syringae as previously shown is a plant pathogen.

\section{Materials and Methods}

\section{Bacterial and fungal strains}

Strains used in this study are listed in Table 1 . Bacterial strains were routinely cultured in liquid or solid (1.5\% agar) Lysogeny Broth (LB) medium at $28^{\circ} \mathrm{C}$ if no other specific temperature is mentioned. Fungal strains were routinely cultured on potato dextrose agar (PDA) at $25^{\circ} \mathrm{C}$.

\section{Insertional mutagenesis of gacA by homologous recombination}

Gene knockout by homologous recombination of $g a c A$ was carried out as previously described ${ }^{27}$. Primers used for insertional mutagenesis of $g a c A$ were used to amplify the gacA gene from $P$. fluorescens In5 and gentamicin resistance gene from pSEVA641. Primers used were block 1: 5'CCATGATTACGCCAAGCTCTAGGGATAACAGGGTAATCCCGACCTGTTATGGCTGGAT GAAGC-3' and

5'-ATCGTAATTATTGGGGACCCGAATGGCCTGGACCATTTCCG-3', block 2: 5'GGAAATGGTCCAGGCCATTCGGGTCCCCAATAATTACGATTTAAATTTGACATAAG-3' and 5'-TTGCCCGGCAAATACCAGGCGGACCGTTGTCCAATTTACCGAAC-3', block 3: 5'GGTAAATTGGACAACGGTCCGCCTGGTATTTGCCGGGC-3’ and

\section{GACGGCCAGTGCCAAGCTCATTACCCTGTTATCCCTACCCCTACCAGCCCGACGCAC-3’.}

The blunt-end-amplified fragments were subsequently ligated using Gibson assembly ® (NEB) into BamHI-digested pEX100T and subsequently transformed into electrocompetent $P$. fluorescens In5 cells as previously described ${ }^{27}$. 
Construction of $m$ Cherry based reporter of gacA gene expression

A reporter strain of $P$. fluorescens In5 harbouring the $g a c A$ promoter region fused to mCherry was constructed as previously described $^{33}$. The primers used were 5'GACGCAAATCAGCGCGTTGTGGCCGGATCCTCTAGAGCACGTAACCGAAGCATTTCAG $-3^{\prime}$ and

5 -

\section{GCTCACCATATGTTTTTCCTCCTAAGCTTGCATGCTCGTGTAATGCCTGTACGAACG-3’.}

The resultant construct was then transformed into P. fluorescens WT and gacA mutant as previously described ${ }^{33}$.

\section{Preparation of plant- and fungal-associated molecules}

The plant phenolic $\beta$-glucosides arbutin, sialicin, phenyl- $\beta$-D- glucopyranoside, esculin and helicin were purchased from Sigma-Aldrich. All compounds were dissolved in DMSO except for arbutin which was dissolved in sterile water. Fungal extracts from four different fungi (Rhizoctonia solani, Fusarium culmorum, Clonostachys rosea, Trichoderma harzianum) and the oomycete Pythium aphanidermatum were prepared as follows. Fungi were cultured on PDA plates and incubated for 57 days at $25^{\circ} \mathrm{C}$. Fungal mycelia were then scraped off each plate and resuspended in $500 \mu 1$ sterile water. Cell lysis was performed in a FastPrep-24 $4^{\mathrm{TM}} 5 \mathrm{G}$ bead beater (MP Biomedicals) using glass beads size $212-300 \mu \mathrm{m} / 425-600 \mu \mathrm{m}$ in the ratio 1:1 (Sigma-Aldrich). After cell disruption, the lysate was transferred to sterile $1.5 \mathrm{ml}$ sterile tube and centrifuged $5 \mathrm{mins}$ at $13,000 \mathrm{~g}$ and the supernatant subsequently used in bioreporter assays. Heat inactivation of fungal extracts was performed by heat treatment at $95^{\circ} \mathrm{C}$ for 10 minutes with a subsequent centrifugation step at 13,000 $\mathrm{g}$ for 5 minutes.

\section{Biomonitoring of gacA and nunF}

A microtiter plate reader assay was used to monitor expression of the gacA and nunF genes. Reporter strains carrying either gacA or nunF on the dual-fluorescence reporter plasmid 
pSEVA237RB were assayed as follows. Bioreporter strains were grown in $10 \mathrm{ml}$ Defined Fusarium Medium (DFM) ${ }^{27}$ supplemented with $0.5 \%$ cellobiose shaking at $200 \mathrm{rpm} 28^{\circ} \mathrm{C}$ overnight. Cells were washed twice with $0.9 \% \mathrm{wv}^{-1} \mathrm{NaCl}$ and resuspended in $0.9 \% \mathrm{wv}^{-1} \mathrm{NaCl}$ to a final $\mathrm{OD}_{600 \mathrm{~nm}}$ of 0.1 . For testing plant phenolic compounds the following was added to each well; $178 \mu \mathrm{LFM}$ supplemented with $0.05 \%$ cellobiose and $2 \mu \mathrm{l}$ of plant phenolic compounds (100 $\mu \mathrm{M}$ final concentration) or $2 \mu \mathrm{l}$ of either trehalose (100 $\mu \mathrm{M}$ final concentration), DMSO (control) or water (control), and $20 \mu \mathrm{l}$ cells or $0.9 \% \mathrm{wv}^{-1} \mathrm{NaCl}$ (control) with an $\mathrm{OD}_{600 \mathrm{~nm}}$ of 0.1 (final $\mathrm{OD}_{600 \mathrm{~nm}}=0.01$ ). For testing fungal extracts compounds the following was added to each well: $173 \mu \mathrm{l}$ DFM supplemented with $0.05 \%$ cellobiose and $7 \mu 1$ of fungal extract or water (control) and $20 \mu 1$ cells or $0.9 \% \mathrm{wv}^{-1} \mathrm{NaCl}$ (control) with an $\mathrm{OD}_{600 \mathrm{~nm}}$ of 0.1 . Growth and fluorescence were measured every hour for 48 hours at $28^{\circ} \mathrm{C}$ in FLUOstar Omega Microplate Reader (BMG LABTECH). Analysis of gacA and nunF gene expression for all experiments were performed using biological triplicates. The average and the standard error of the mean (SE) was calculated and the graphs show the average and the average plus or minus SE.

\section{Culturing experiment with different carbon sources at $10^{\circ} \mathrm{C}, 15^{\circ} \mathrm{C}, 20^{\circ} \mathrm{C}$ and $28^{\circ} \mathrm{C}$}

To investigate the effect of different carbon sources on secondary metabolite production, $P$. fluorescens In5 was grown overnight in DFM supplemented with $0.5 \% \mathrm{wv}^{-1}$ cellobiose, shaking 200 $\mathrm{rpm}$ at $28^{\circ} \mathrm{C}$. Cells were washed twice with $0.9 \% \mathrm{wv}^{-1} \mathrm{NaCl}$ and resuspended to an $\mathrm{OD}_{600 \mathrm{~nm}}=1.0$ and $2 \mathrm{ml}$ added to $100 \mathrm{ml}$ Erlenmeyer flasks containing either $0.5 \% \mathrm{wv}^{-1}$ trehalose, glycerol, cellobiose, and glucose. Flasks were incubated 48 hours shaking $200 \mathrm{rpm}$ at either $10^{\circ} \mathrm{C}, 15^{\circ} \mathrm{C}, 20^{\circ} \mathrm{C}$, or $28^{\circ} \mathrm{C}$. Analysis of secondary metabolite production was performed using biological triplicates. Peptide extraction and Liquid Chromatography - High Resolution Mass Spectrometry (LC-HRMS) Metabolite extraction and LC-HRMS analysis was conducted as described previously ${ }^{27}$. Relative abundance represent the peak area in the chromatogram of the extracted ion per total phospholipid 
331 (per cell). Total phospholipids is an accepted measure of living biomass since this it is proportional to total membrane area.

333

334 Acknowledgments

335 This work was supported by the Villum Foundation grant VKR7310 (Microbial Communication-A

336 Key to the Development of Novel Sustainable Agri- and Aquaculture Practices Using Biological

337 Control Bacteria). We would like to thank Dr Birgit Jensen (University of Copenhagen, Denmark)

338 for kindly providing the fungal strains Trichoderma harzianum, Clonostachys rosea and Fusarium

339 culmorum. We also thank the Standard European Vector Architecture (SEVA) platform for 340 providing the plasmid pSEVA641.

\section{Conflict of interest}

342 The authors declare no conflict of interest. 


\section{References}

1. Thomashow LS, Kwak YS, Weller DM. 2019. Root-associated microbes in sustainable agriculture: models, metabolites and mechanisms. Pest Manag Sci 75:2360-2367.

2. Berendsen RL, Pieterse CM, Bakker PA. 2012. The rhizosphere microbiome and plant health. Trends Plant Sci 17:478-486.

3. Weller DM. 2007. Pseudomonas biocontrol agents of soilborne pathogens: looking back over 30 years. Phytopathology 97:250-256.

4. Raaijmakers JM, Vlami M, de Souza JT. 2002. Antibiotic production by bacterial biocontrol agents. Antonie Van Leeuwenhoek 81:537-547.

5. Masschelein J, Jenner M, Challis GL. 2017. Antibiotics from Gram-negative bacteria: A comprehensive overview and selected biosynthetic highlights. Nat Prod Rep 34:712-783.

6. Gross H, Loper JE. 2009. Genomics of secondary metabolite production by Pseudomonas spp. Nat Prod Rep 26:1408-1446.

7. Zhao H, Liu YP, Zhang LQ. 2019. In silico and genetic analyses of cyclic lipopeptide synthetic gene clusters in Pseudomonas sp. 11K1. Front Microbiol 10:544.

8. Hutchison ML, Gross DC. 1997. Lipopeptide phytotoxins produced by Pseudomonas syringae pv. syringae: comparison of the biosurfactant and ion channel-forming activities of syringopeptin and syringomycin. Mol Plant Microbe Interact 10:347-354.

9. Michelsen CF, Watrous J, Glaring MA, Kersten R, Koyama N, Dorrestein PC, Stougaard P. 2015. Nonribosomal peptides, key biocontrol components for Pseudomonas fluorescens In5, isolated from a Greenlandic suppressive soil. mBio 6:e0079.

10. Scaloni A, Dalla Serra M, Amodeo P, Mannina L, Vitale RM, Segre AL, Cruciani O, Lodovichetti F, Greco ML, Fiore A, Gallo M, D'Ambrosio C, Coraiola M, Menestrina G, Graniti A, Fogliano V. 2004. Structure, conformation and biological activity of a novel lipodepsipeptide from Pseudomonas corrugata: cormycin A. Biochem J 384:25-36. 
11. van der Voort M, Meijer HJ, Schmidt Y, Watrous J, Dekkers E, Mendes R, Dorrestein PC, Gross H, Raaijmakers JM. 2015. Genome mining and metabolic profiling of the rhizosphere bacterium Pseudomonas sp. SH-C52 for antimicrobial compounds. Front Microbiol 6:693.

12. Schmidt Y, van der Voort M, Crüsemann M, Piel J, Josten M, Sahl HG, Miess H, Raaijmakers JM, Gross H. 2014. Biosynthetic origin of the antibiotic cyclocarbamate brabantamide A (SB-253514) in plant-associated Pseudomonas. Chembiochem. Jan 24;15(2):259-66.

13. Cheng X, de Bruijn I, van der Voort M, Loper JE, Raaijmakers JM. 2013. The Gac regulon of Pseudomonas fluorescens SBW25. Environ Microbiol Rep 5:608-619.

14. Workentine ML, Chang L, Ceri H, Turner RJ. 2009. The GacS-GacA two-component regulatory system of Pseudomonas fluorescens: A bacterial two-hybrid analysis. FEMS Microbiol Lett 292:50-56.

15. Wei X, Huang X, Tang L, Wu D, Xu Y. 2013. Global control of GacA in secondary metabolism, primary metabolism, secretion systems, and motility in the rhizobacterium Pseudomonas aeruginosa M18. J Bacteriol 195:3387-3400.

16. Koch B, Nielsen TH, Sørensen D, Andersen JB, Christophersen C, Molin S, Givskov M, Sørensen J, Nybroe O. 2002. Lipopeptide production in Pseudomonas sp. strain DSS73 is regulated by components of sugar beet seed exudate via the Gac two-component regulatory system. Appl Environ Microbiol 68:4509-4516.

17. de Bruijn I, Raaijmakers JM. 2009. Diversity and functional analysis of LuxR-type transcriptional regulators of cyclic lipopeptide biosynthesis in Pseudomonas fluorescens. Appl Environ Microbiol 75:4753-4761.

18. Kitten T, Kinscherf TG, McEvoy JL, Willis DK. 1998. A newly identified regulator is required for virulence and toxin production in Pseudomonas syringae. Mol Microbiol 28:917-929. 
19. Cha JY, Lee DG, Lee JS, Oh JI, Baik HS. 2012. GacA directly regulates expression of several virulence genes in Pseudomonas syringae pv. tabaci 11528. Biochem Biophys Res Commun 417:665-672.

20. Wang Z, Huang X, Liu Y, Yang G, Liu Y, Zhang X. 2017. GacS/GacA activates pyoluteorin biosynthesis through Gac/Rsm-RsmE cascade and RsmA/RsmE-driven feedback loop in Pseudomonas protegens H78. Mol Microbiol 105:968-985.

21. Song C, Aundy K, van de Mortel J, Raaijmakers JM. 2014. Discovery of new regulatory genes of lipopeptide biosynthesis in Pseudomonas fluorescens. FEMS Microbiol Lett 356:166-175.

22. Licciardello G, Caruso A, Bella P, Gheleri R, Strano CP, Anzalone A, Trantas EA, Sarris PF, Almeida NF, Catara V. 2018. The LuxR regulators PcoR and RfiA co-regulate antimicrobial peptide and alginate production in Pseudomonas corrugata. Front Microbiol 9:521.

23. Licciardello G, Strano CP, Bertani I, Bella P, Fiore A, Fogliano V, Venturi V, Catara V. 2012. $N$-acyl-homoserine-lactone quorum sensing in tomato phytopathogenic Pseudomonas spp. is involved in the regulation of lipodepsipeptide production. J Biotechnol 159:274-282.

24. Yan Q, Wu XG, Wei HL, Wang HM, Zhang LQ. 2009. Differential control of the Pcol/PcoR quorum-sensing system in Pseudomonas fluorescens 2P24 by sigma factor RpoS and the GacS/GacA two-component regulatory system. Microbiol Res 164:18-26.

25. Song C, van der Voort M, van de Mortel J, Hassan KA, Elbourne LD, Paulsen IT, Loper JE, Raaijmakers JM. 2015. The Rsm regulon of plant growth-promoting Pseudomonas fluorescens SS101: Role of small RNAs in regulation of lipopeptide biosynthesis. Microb Biotechnol 8:296-310.

26. Lu SE, Scholz-Schroeder BK, Gross DC. 2002. Characterization of the $s a l A$, $s y r F$, and $s y r G$ regulatory genes located at the right border of the syringomycin gene cluster of Pseudomonas syringae pv. syringae. Mol Plant Microbe Interact 15:43-53. 
27. Hennessy RC, Phippen CBW, Nielsen KF, Olsson S, Stougaard P. 2017. Biosynthesis of the antimicrobial cyclic lipopeptides nunamycin and nunapeptin by Pseudomonas fluorescens strain In5 is regulated by the LuxR-type transcriptional regulator NunF. MicrobiologyOpen 6:e516.

28. Vaughn VL, Gross DC. 2016. Characterization of $s a l A$, $s y r F$, and $s y r G$ genes and attendant regulatory networks involved in plant pathogenesis by Pseudomonas syringae pv. syringae B728a. PLoS One 11:e0150234.

29. Mo YY, Gross DC. 1991. Plant signal molecules activate the $s y r B$ gene, which is required for syringomycin production by Pseudomonas syringae pv. syringae. J Bacteriol 173:57845792.

30. Wang N, Lu SE, Wang J, Chen ZJ, Gross DC. 2006. The expression of genes encoding lipodepsipeptide phytotoxins by Pseudomonas syringae pv. syringae is coordinated in response to plant signal molecules. Mol Plant Microbe Interact 19:257-269.

31. Hennessy RC, Stougaard P, Olsson S. 2017. A Microplate Reader-Based System for Visualizing Transcriptional Activity During in vivo Microbial Interactions in Space and Time. Sci Rep 7:281.

32. Michelsen CF, Stougaard P. 2011. A novel antifungal Pseudomonas fluorescens isolated from potato soils in Greenland. Curr Microbiol 62:1185-1192.

33. Hennessy RC, Christiansen L, Olsson S, Stougaard P. 2018. A broad-host range dualfluorescence reporter system for gene expression analysis in Gram-negative bacteria. J Microbiol Methods 144:173-176.

34. Choi KH, Kumar A, Schweizer HP. 2006. A 10-min method for preparation of highly electrocompetent Pseudomonas aeruginosa cells: Application for DNA fragment transfer between chromosomes and plasmid transformation. J Microbiol Methods 64:391-397. 
35. Jensen B, Knudsen IMB, Jensen DF. 2000. Biological seed treatment of cereals with fresh and long-term stored formulations of Clonostachys rosea: biocontrol efficacy against Fusarium culmorum. Eur J Plant Pathol 106:233-242.

36. Jensen DF, Knudsen IMB, Lübeck M, Mamarabadi M, Hockenhull J, Jensen B. 2007. Development of a biocontrol agent for plant disease control with special emphasis on the near commercial fungal antagonist Clonostachys rosea strain "IK726". Aus Plant Pathol 36:95-101.

37. Ahmad JS, Baker R. 1987. Rhizosphere competance of Trichoderma harzianum, Phytopathology 77:182. 


\section{Legends to Figures:}

Fig. 1. Expression from the nunF promotor, synthesis of nunamycin, nunapeptin, and brabantamides, and antifungal activity is dependent on the GacA product. A, Production of nunapeptin, nunamycin, and brabantamide-like compounds in wild type $P$. fluorescens In5 (1) and in gacA knock out mutant (2). Y-axis shows ion counts, i.e. the peak area of extracted ion chromatograms for each of the specific analytes. Triplicate cultures were extracted and the concentration of nunapeptin, nunamycin, and brabantamides was measured. B, Inhibition of Rhizoctonia solani hyphal growth in the presence of wild type (WT) P. fluorescens In5 cells and gacA knock out mutant $(\Delta \mathrm{gacA})$ cells. The growth of $R$. solani hyphae in the presence and in the absence of $P$. fluorescens In5 was measured and the percentage inhibition of radial growth (PIRG) was calculated. C, Analysis of nunF (PnunF) and gacA (PgacA) promotors in P. fluorescens In5 wild type (WT) and gacA knock out mutant $(\Delta \mathrm{gacA})$ cells using promotor::mCherry promotor fusions. Cells were grown at $28^{\circ} \mathrm{C}$ in DFM medium supplemented with glucose $(0.04 \% \mathrm{w} / \mathrm{v})$ in a 96 well microtiter format with shaking. Growth and mCherry fluorescence was measured every hour for 47 hours in a FLUOstar Omega Microplate Reader. Lines represent average of three biological repetitions. Solid lines show the averages of fluorescence per cell and the dotted lines in the same color represent the average plus/minus the standard error of the mean.

Fig. 2. Response of gacA and nunF promotors to fungal and plant associated molecules. gacA (A) and $n u n F($ B) promotors fused to $m$ Cherry and analyzed in $P$. fluorescens In5 cultivated in 96well microtiter plates in DFM supplemented with plant phenolics (arbutin, salicin, or phenyl- $\beta$-Dglucopyranoside ("phenol" in the legend next to the curves)), fungal associated trehalose, or glucose. Negative controls were blank, water (arbutin is dissolved in water), and DMSO (salicin and phenyl- $\beta$-D-glucopyranoside are dissolved in DMSO). Growth and fluorescence were measured every hour for 47 hours at $28^{\circ} \mathrm{C}$ in a FLUOstar Omega Microplate Reader. Lines represent average 
of three biological repetitions. Solid lines show the averages of fluorescence per cell and the dotted lines in the same color represent the average plus/minus the standard error of the mean.

Fig. 3. Response of $\operatorname{gacA}$ and $n u n F$ promotors to fungal extracts. gacA (A) and nunF (B) promotors fused to $m$ Cherry and analyzed in $P$. fluorescens In5 cultivated in 96-well microtiter plates in DFM supplemented with extracts from Fusarium culmorum (F.c.), Trichoderma harzianum (T.h.), and Clonostachys rosea (C.r.). Positive (trehalose) and negative (water, blank) controls were included. T.h. inact. and C.r. inact. indicate fungal extracts inactivated by heating to $95^{\circ} \mathrm{C}$ for 10 minutes. Growth and fluorescence were measured every hour for 47 hours at $28^{\circ} \mathrm{C}$ in a FLUOstar Omega Microplate Reader. Lines represent average of three biological repetitions. Solid lines show the averages of fluorescence per cell and the dotted lines in the same color represent the average plus/minus the standard error of the mean.

Fig. 4. Response of $P$. fluorescens In5 nunF and $P$. syringae pv. syringae syrF promotors to a fungal extract, plant phenolics, trehalose, and glucose. $n u n F(\mathbf{A})$ and $\operatorname{syr} F(\mathbf{B})$ promotors fused to $m$ Cherry and analyzed in $P$. fluorescens In5 and P. syringae, respectively. Cells were cultivated in 96-well microtiter plates in DFM supplemented with plant phenolics (arbutin or phenyl- $\beta$-Dglucopyranoside ("phenol" in the legend next to the curves)), fungal associated trehalose, or glucose. Negative controls were blank and water. Growth and fluorescence were measured every hour for 47 hours at $28^{\circ} \mathrm{C}$ in a FLUOstar Omega Microplate Reader. Lines represent average of three biological repetitions. Solid lines show the averages of fluorescence per cell and the dotted lines in the same color represent the average plus/minus the standard error of the mean. 
504 Fig. 5. Influence of temperature on P. fluorescens In5 gacA and nunF promotors. nunF (A, C, 505 E, G) and $g a c A(\mathbf{B}, \mathbf{D}, \mathbf{F}, \mathbf{H})$ promotors fused to mCherry and analyzed in P. fluorescens In5 506 cultivated in 96-well microtiter plates in DFM supplemented with 0.5\% wv-1 trehalose, glycerol, or 507 glucose. Cells were cultivated at $10^{\circ} \mathrm{C}(\mathbf{A}, \mathbf{B}), 15^{\circ} \mathrm{C}(\mathbf{C}, \mathbf{D}), 20^{\circ} \mathrm{C}(\mathbf{E}, \mathbf{F})$, and $28^{\circ} \mathrm{C}(\mathbf{G}, \mathbf{H})$. Growth 508 and fluorescence were measured every hour for 47 hours in a FLUOstar Omega Microplate Reader. $509 \mathrm{X}$ axis, hours; $\mathrm{Y}$ axis, mCherry/cell density. Lines represent average of three biological repetitions. 510 Solid lines show the averages of fluorescence per cell and the dotted lines in the same color 511 represent the average plus/minus the standard error of the mean.

Fig. 6. Effect of carbon source and temperature on secondary metabolite production by $P$. fluorescens In5. P. fluorescens In5 was grown overnight in DFM supplemented with $0.5 \%$ wv-1 cellobiose, shaking $200 \mathrm{rpm}$ at $28^{\circ} \mathrm{C}$. Cells were washed twice with $0.9 \%$ wv-1 $\mathrm{NaCl}$ and resuspended to an OD600nm=1.0 and $2 \mathrm{mls}$ added to $100 \mathrm{ml}$ Erlenmeyer flasks containing either $0.5 \%$ wv-1 trehalose, glycerol, or glucose. Flasks were incubated 48 hours shaking $200 \mathrm{rpm}$ at either $10^{\circ} \mathrm{C}, 15^{\circ} \mathrm{C}, 20^{\circ} \mathrm{C}$, or $28^{\circ} \mathrm{C}$. Production of nunapeptin (A), nunamycin (B) and brabantamides (C) was performed using biological triplicates. Bars represent the average of the triplicates, triangles are average plus standard error of the mean (SE), and squares are average minus SE. Peptide extraction and Liquid Chromatography - High Resolution Mass Spectrometry (LC-HRMS)

522 analysis was performed as described previously (27). Relative abundance represent the peak area in 523 the chromatogram of the extracted ion per total phospholipid.

Fig. 7. Model for how synthesis of nunamycin and nunapeptin is regulated. In step 1 (1), the 526 fungus and P. fluorescens In5 (In5) are far away from each other. P. fluorescens In5 synthesizes 527 constitutively small amounts of GacA, NunF, nunamycin and nunapeptin. The main carbon storage 
in the fungus is fat. Concentration of glucose (Glu), trehalose (Tre) and glycerol (Gly) is low and turgor is high. The bacterium and fungus have come closer in step 2 (2) where nunamycin and nunapeptin are still produced constitutively at low levels. Nunamycin and nunapeptin permeabilize the fungal cell membrane and the fungus starts to leak cellular constituents. NunF is induced by leaking glucose, glycerol, and trehalose from the fungal hyphae whereas GacA is expressed at low, constitutive level. The fungus tries to restore turgor pressure by converting fat to glycerol. At the same time, trehalose is synthesized in order to protect membranes and proteins from drying. Glycerol, trehalose and glucose leak out of the cell and are being taken up by the bacterium. The uptake of compounds from step 2 triggers upregulation of nunamycin and nunapeptin synthesis and possibly also export of the peptides in step $3(\mathbf{3})$. GacA is still expressed at low, constitutive level, but leaking glucose, glycerol, and trehalose induce NunF expression resulting in increased amounts of nunamycin and nunapeptin leading to further permeabilization of the membrane and leakage of more intracellular components. The fungus tries to stabilize turgor pressure as in step 2, but as the membrane is compromised by increased amounts of nunamycin and nunapeptin, the turgor pressure drops and the fungus starts to die while the bacterial growth rate increases. 
Table 1 Strains and plasmids used in this study

\begin{tabular}{|c|c|c|}
\hline Strains & Relevant Characteristics & Reference \\
\hline \multicolumn{3}{|l|}{ Plasmid } \\
\hline pUX-BF13 & RK6 replicon-based helper plasmid; $\mathrm{Ap}^{\mathrm{r}}$ & 34 \\
\hline $\mathrm{pEX} 100 \mathrm{~T}$ & oriT bla sacB & 9 \\
\hline pEX100T::gacA::Gm ${ }^{\mathrm{r}}$ & oriT bla $\mathrm{sac} B$ gacA $; \mathrm{Gm}^{\mathrm{r}} \mathrm{Amp}^{\mathrm{r}}$ & This study \\
\hline pSEVA237RB & $\mathrm{Kan}^{\mathrm{r}} ;$ mCherry and EBFB2 genes & 33 \\
\hline pSEVA237RB::PgyrB & $\mathrm{Kan}^{\mathrm{r}} ;$ mCherry gene, gyrB promoter $\left(P_{g y r B}\right)$ fused to EBFP2 & 33 \\
\hline pSEVA237R $:: P_{\text {gacA }} \mathrm{B}::$ Pgyr $B$ & $\mathrm{Kan}^{\mathrm{r}} ;$ gacA promoter $\left(P_{\mathrm{gacA}}\right)$ fused to mCherry gene, $\operatorname{Pgyr} B:: E B F P 2$ & This study \\
\hline pSEVA237R::P $P_{\text {nun }} \mathrm{B}:: P g y r B$ & $\mathrm{Kan}^{\mathrm{r}} ;$ nunF promoter $\left(P_{\mathrm{nunF}}\right)$ fused to mCherry gene, $\operatorname{Pgyr} B:: E B F P 2$ & 33 \\
\hline \multicolumn{3}{|l|}{ Bacterial } \\
\hline Escherichia coli DH5 & endAl hsdR17 supE44 thi-1 recAl U169 deoR & NEB, UK \\
\hline Pseudomonas fluorescens In5 & Wild type & 9 \\
\hline P. fluorescens In5 & $\Delta$ nunF & 31 \\
\hline P. fluorescens In5 & $\triangle g a c A$ & This study \\
\hline \multicolumn{3}{|l|}{ Fungal } \\
\hline Rhizoctonia solani & Wild type & 32 \\
\hline Pythium aphanidermatum & Wild type & 32 \\
\hline Fusarium culmorum & Wild type & 35 \\
\hline Trichoderma harzianum & Wild type & 37 \\
\hline Clonostachys rosea & Wild type & 36 \\
\hline
\end{tabular}


A

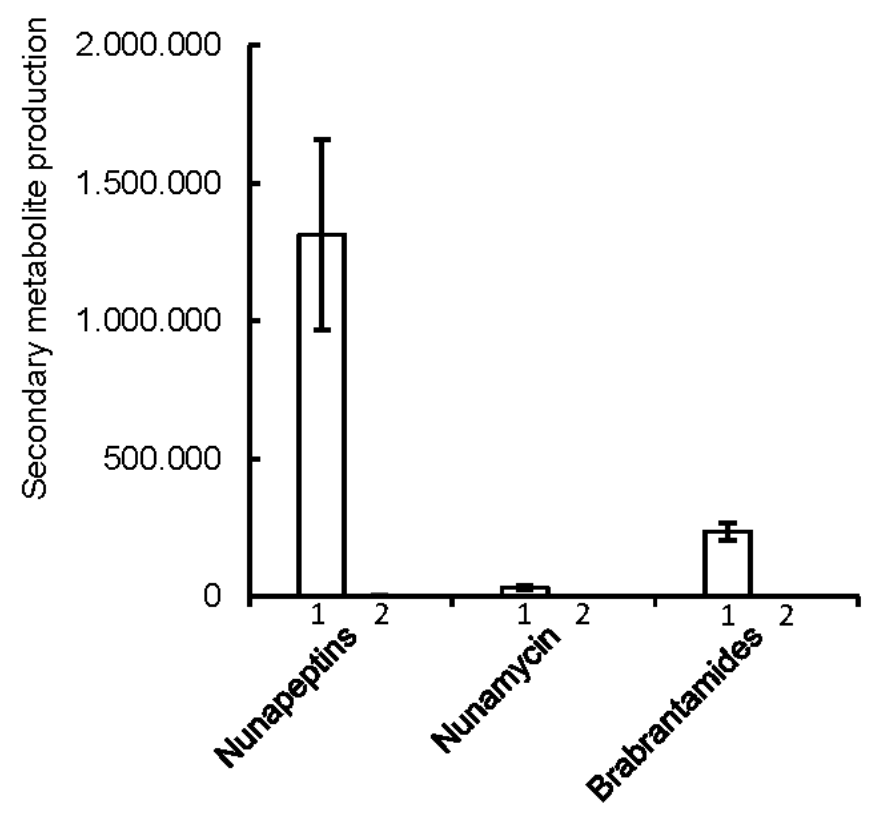

C
B

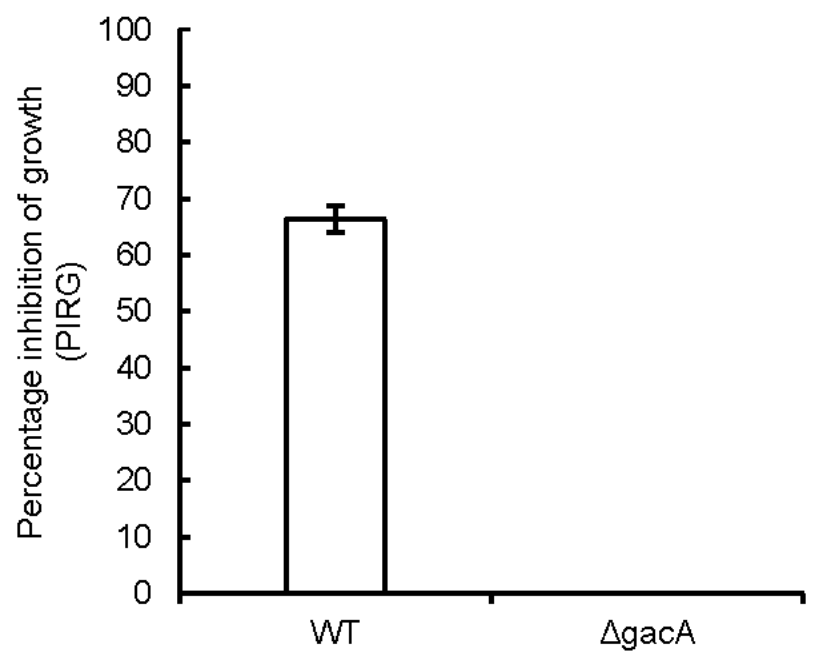

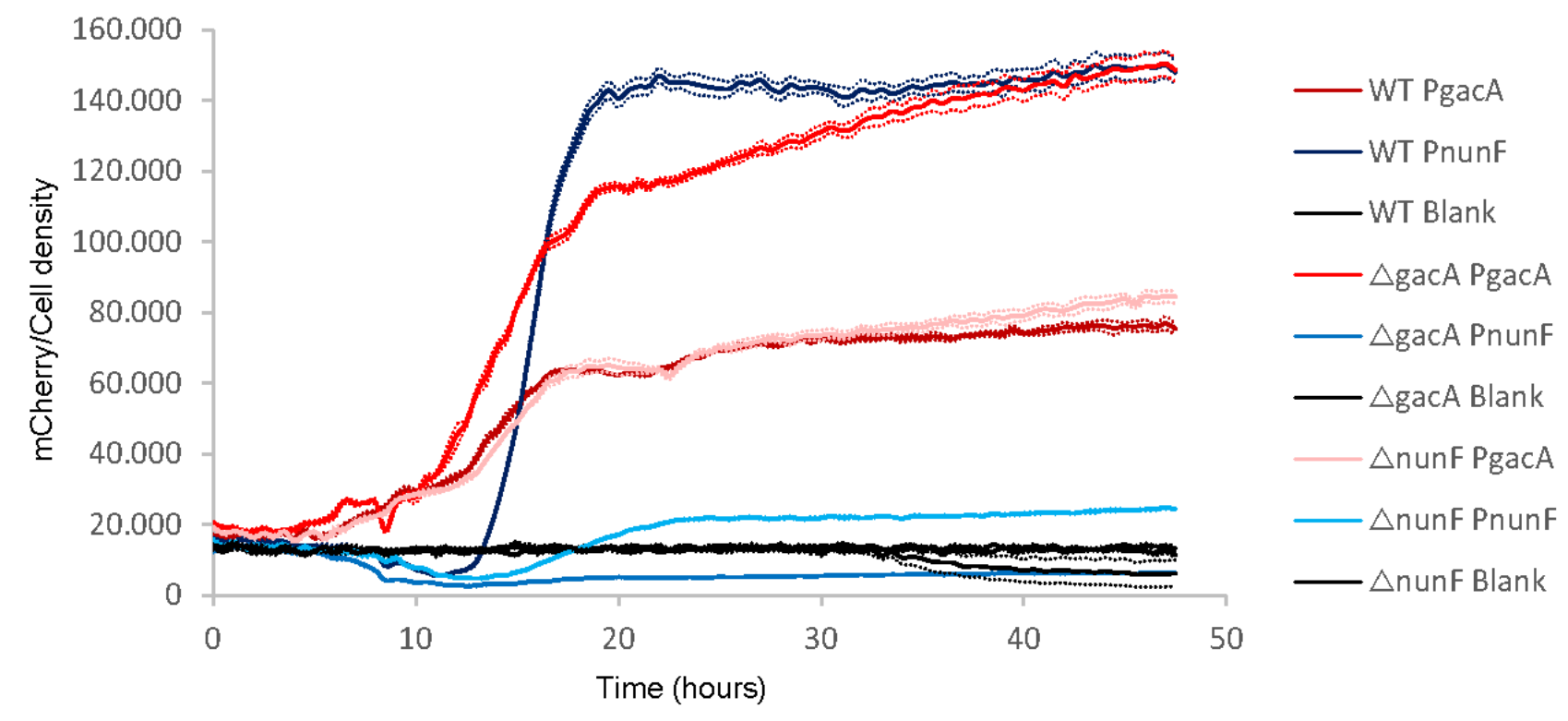

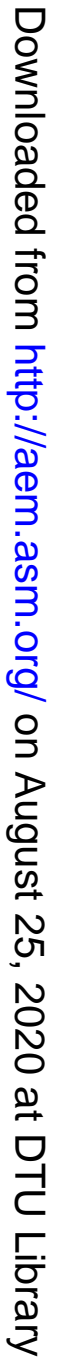





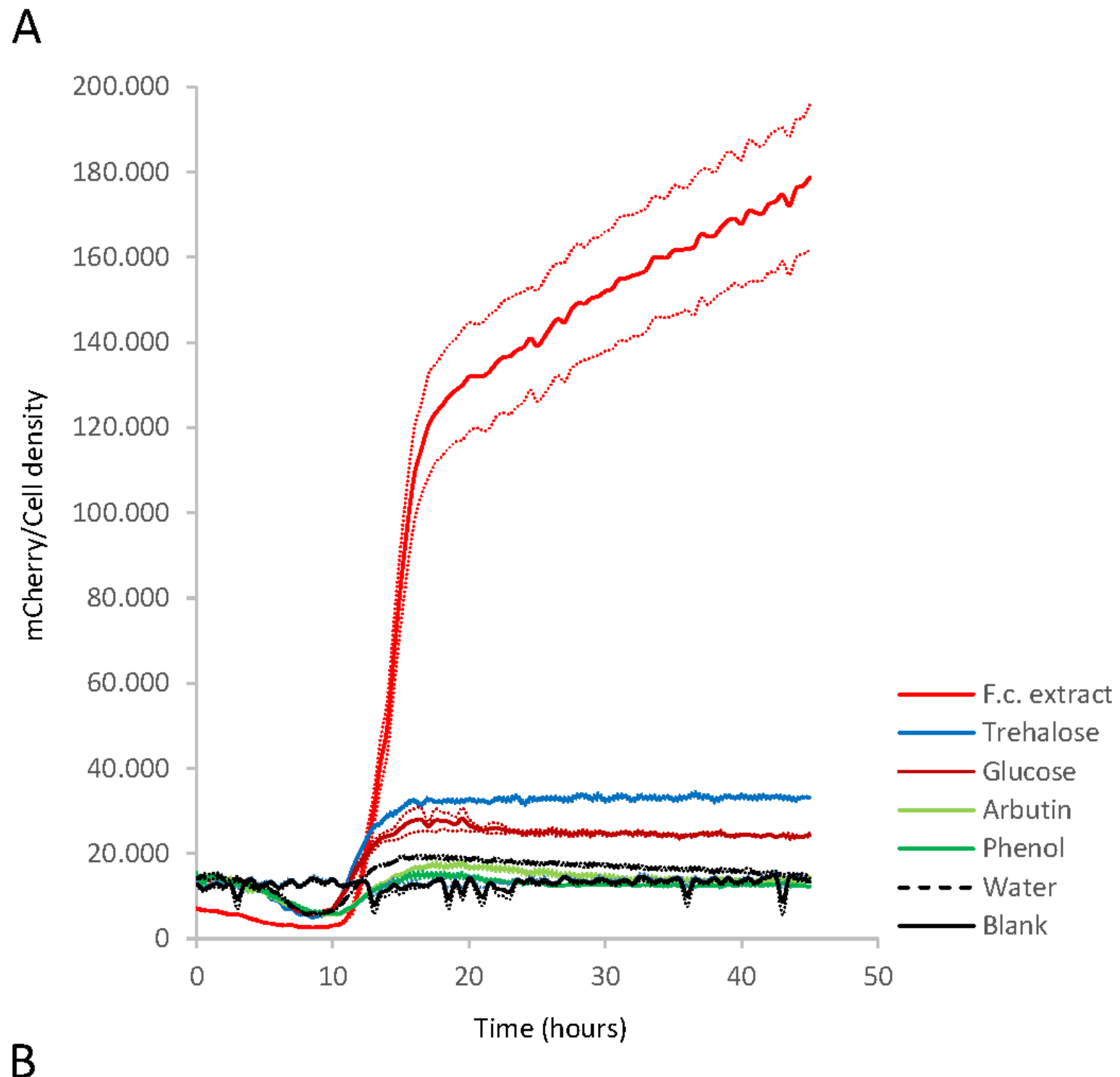

B

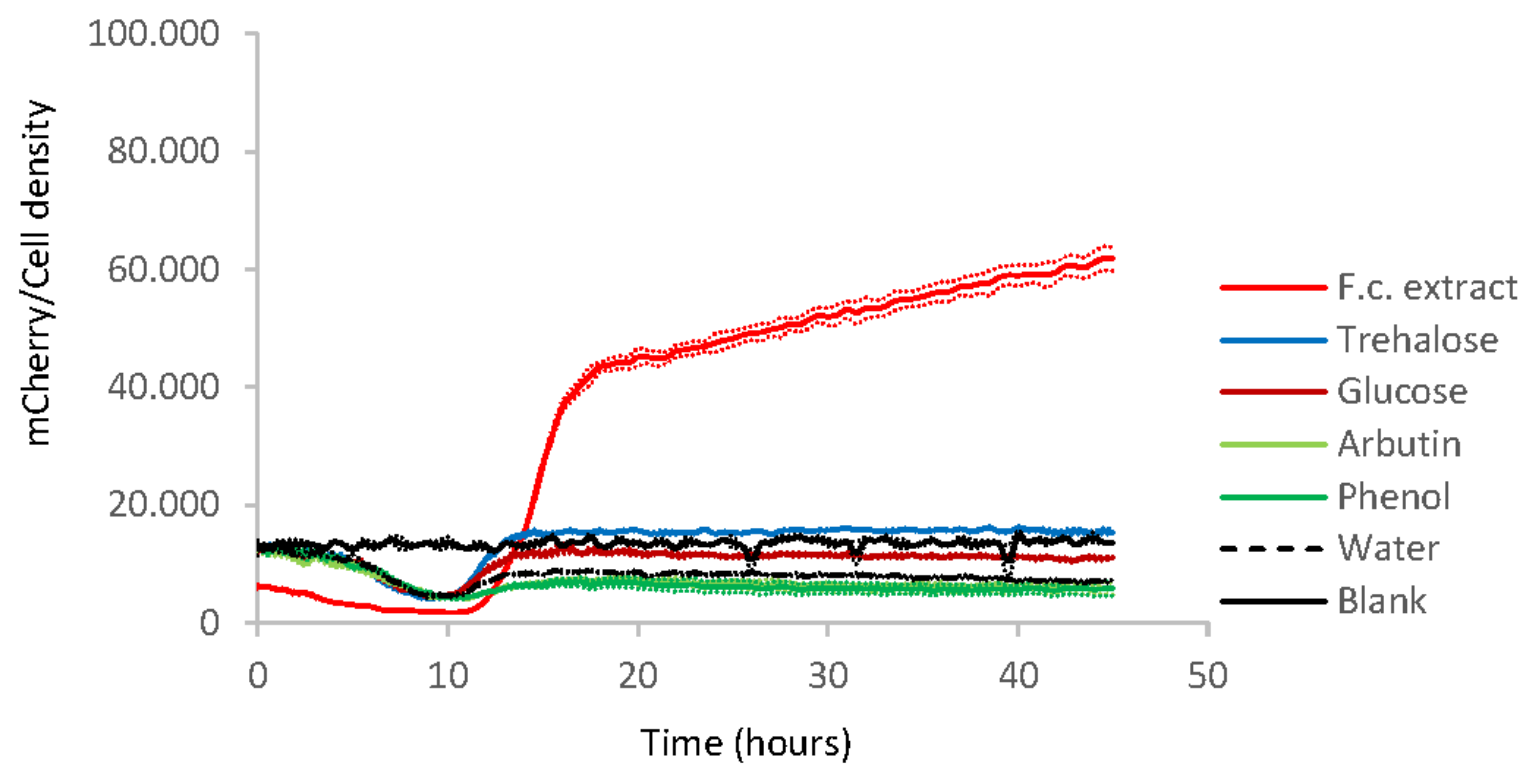




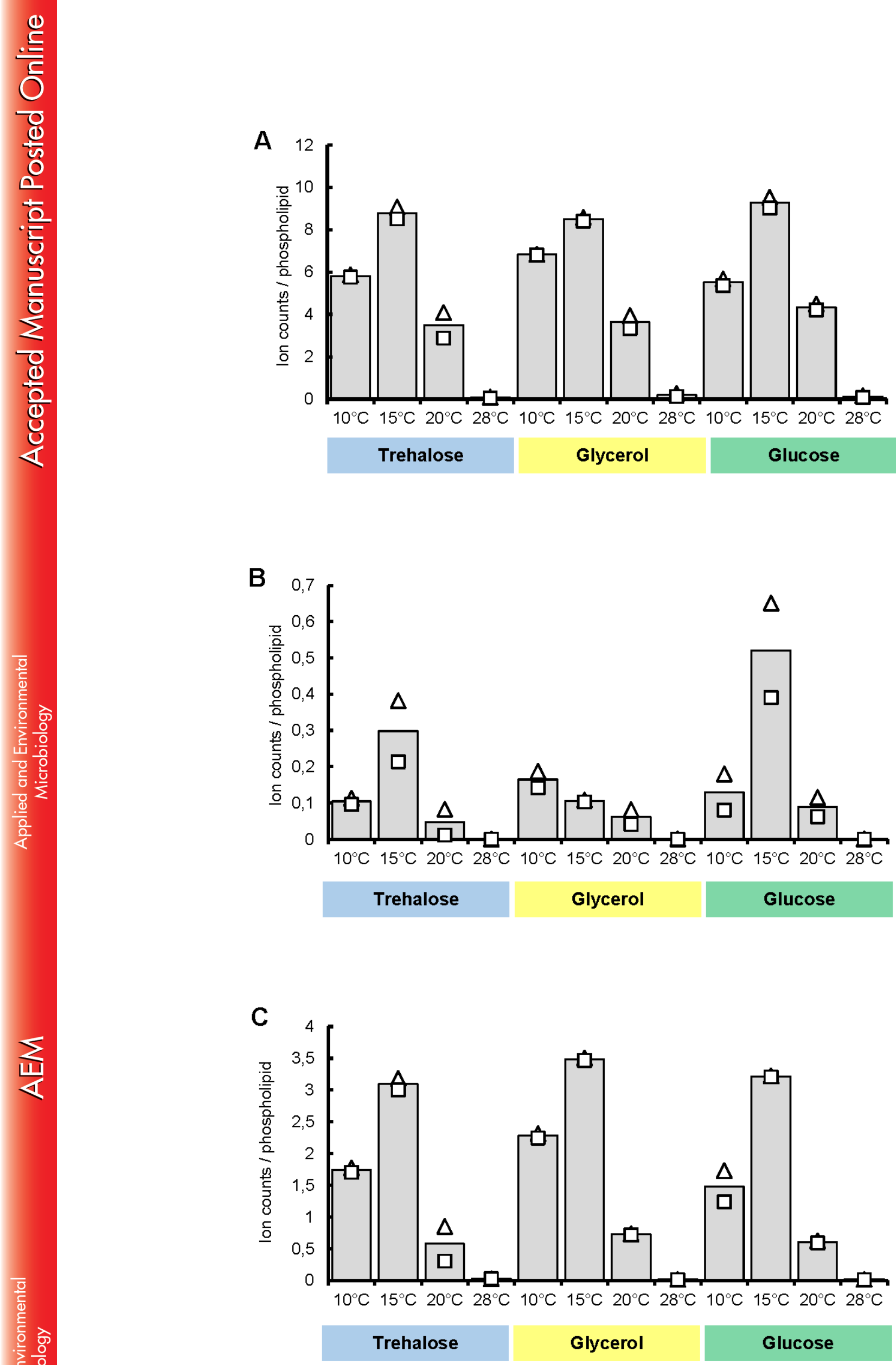
